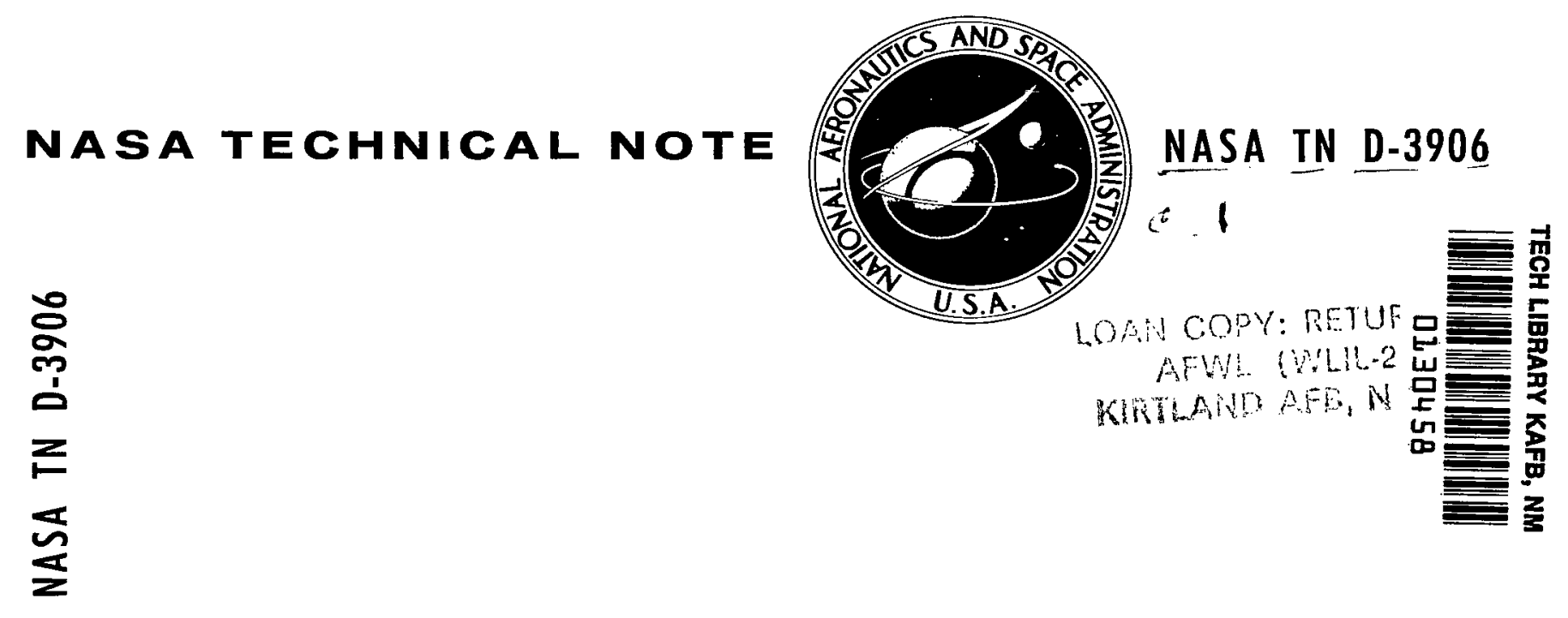

\title{
SYNTHESIS OF HIGHER ORDER HYDROCARBONS ON HOT TUNGSTEN FILAMENTS
}

by H. Shapiro and B. N. Paxson

Goddard Space Flight Center

Greenbelt, $M d$.

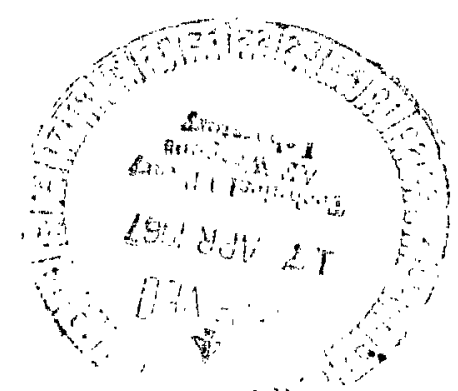

national aeronautics and SPACE adMINISTRATION - WASHINGTON, D. C. - APRIL 1967 
NASA TN D-3906

\section{SYNTHESIS OF HIGHER ORDER HYDROCARBONS}

\section{ON HOT TUNGSTEN FILAMENTS}

By H. Shapiro and B. N. Paxson

Goddard Space Flight Center

Greenbelt, Md. 


\begin{abstract}
This study uses a quadrupole mass spectrometer of sensitivity $10^{-15}$ torr ( $\mathrm{N}_{2}$ equivalent) to show the synthesis of acetylene, ethane, propylene and propane from methane on a hot tungsten filament. The study investigates the relationship between the partial pressures of these hydrocarbons and the filament temperature. The constancy of the product composition for a given temperature at two partial pressures of methane is also demonstrated. Acetylene, the most abundant of the synthesized hydrocarbons, is found to have a partial pressure only about one decade less than the parent methane. The measurement of total pressure in the ultra high vacuum regions by hot filament gauges may be erroneous due to this kind of synthesis.
\end{abstract}




\section{CONTENTS}

Abstract................... ii

INTRODUCTION. . . . . . . . . . . . . 1

APPARATUS................... 1

EXPERIMENTAL PROCEDURE . . . . . . . 2

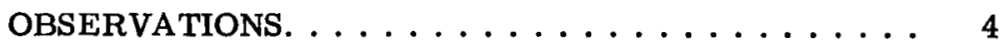

CONCLUSIONS. ................ 6

References.................. 6 


\title{
SYNTHESIS OF HIGHER ORDER HYDROCARBONS ON HOT TUNGSTEN FILAMENTS*
}

\author{
by \\ H. Shapiro and B. N. Paxson \\ Goddard Space Flight Center
}

\section{INTRODUCTION}

Where a delicate equilibrium is being maintained, the mere act of measurement of one of the parameters may disturb the equilibrium, rendering the desired measurement unreliable. Such sources of error, while common, are not always easily recognized. This is believed to be the case in the situation discussed in this report. The measurement of ultra-high vacuum by means of hot filament gauges, and the analysis of the residual gas by means of the mass spectrometer both introduce into the vacuum products that were not originally present. This phenomenon has been previously observed (Reference 1) and has most often been ascribed to the presence of carbon or carbides (found as impurities in tungsten filaments) and its reaction with $\mathrm{H}_{2} \mathrm{O}$ or $\mathrm{O}_{2}$ (Reference 2). This study attempts to describe the recombination products which are formed as a result of these reactions, the subsequent formation of $\mathrm{CH}_{4}$ and the fragmentation of $\mathrm{CH}_{4}$ upon contact with a hot tungsten filament. The study shows that these fragments recombine to synthesize higher order hydrocarbons.

\section{APPARATUS}

The equipment, sche matically shown in Figure 1 , consists of an ion-pumped vacuum system that is capable of achieving vacua in the $10^{-9}$ torr region in a $12^{\prime \prime}$ glass bell jar above the pump. A Wheeler flanged type collar carries all of the needed feedthroughs and provides a metal-to-metal seal from the pump throat. A micrometer-controlled variable leak provides the gas inlet to the system. The pressure gauge

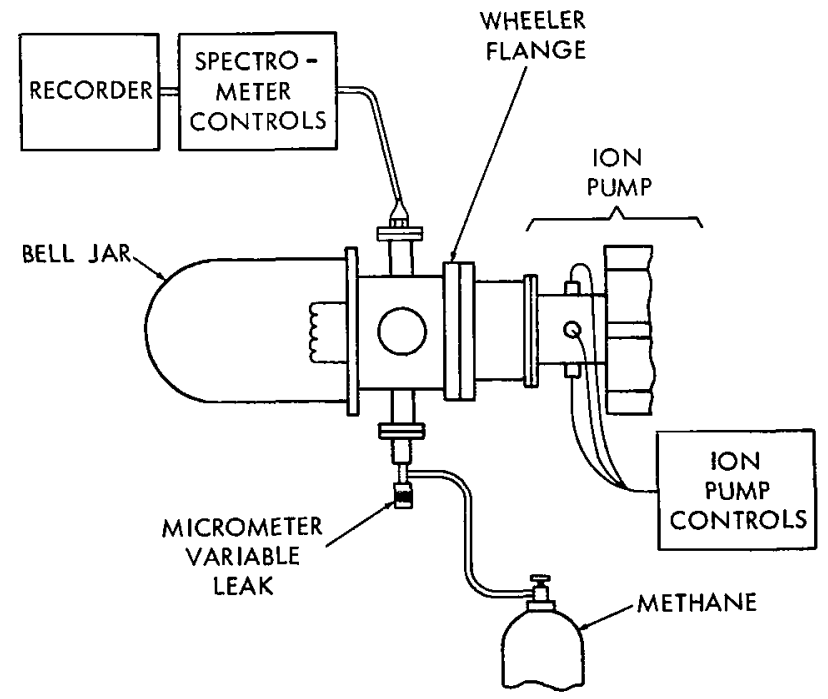

Figure 1-Schematic layout of the equipment. The spectrometer filament is exaggerated to show its relative position.

* Also published in Vacu $u m, 1966$. 
is part of the pump control and reads the current to the anodes interpolated in torr. The mass spectrometer is of the quadrupole type with an advertised sensitivity for $\mathrm{N}_{2}$ better than $10^{-14}$ torr partial pressure, and resolution better than twice the mass number being scanned, 150 at $\mathrm{m} / \mathrm{e} 75$, in the mass range used. The ionizer of the spectrometer is mounted directly into the vacuum under investigation and its tungsten filament provides the hot surface where the reactions to be described take place. The entire system is unbaked and has a long, varied history of use in vacuum studies. Tank gas was used and no attempt to purify the stream was either undertaken or considered necessary, since a gas chromatographic analysis found no contaminants in the range of interest.

\section{EXPERIMENTAL PROCEDURE}

The system was closed and pumpdown was allowed to continue for 72 hours, at which time a base pressure of $2.5 \times 10^{-8}$ torr was recorded. A scan of the residuals was made (Figure 2) and the average sensitivity of the spectrometer for this scan was computed to be $5 \times 10^{-12}$ torr/ division. Methane was bled into the vacuum through a tube which was differentially pumped to minimize residual air inbleed, and then through the variable leak, until the pressure increased to $1 \times 10^{-7}$ torr.

Equilibrium was maintained at this pressure for about 30 minutes, and a scan (Figure 3) of the background containing methane was recorded. The procedure was repeated after raising the internal pressure to $6 \times 10^{-7}$ torr and a scan (Figure 4) was recorded at that pressure. These steps were repeated daily for two weeks and the average of the data was compiled for m/e 1-60. No peaks were discernible on any scan from $\mathrm{m} / \mathrm{e}$ 60-500.

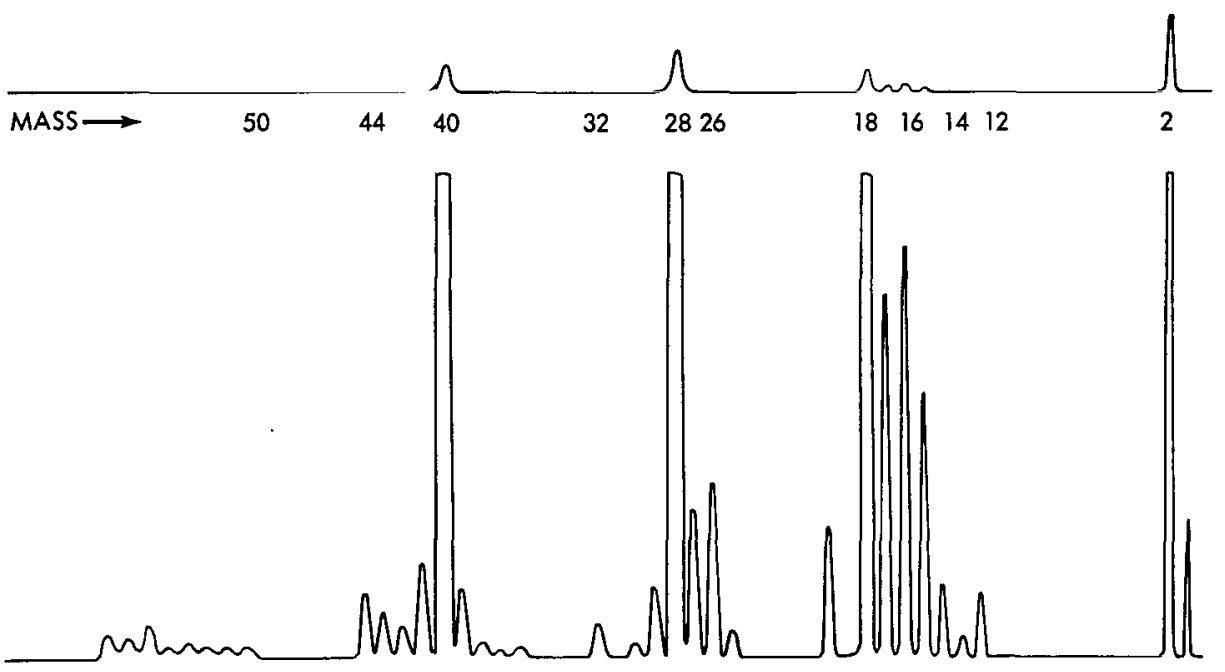

Figure 2-Residual gas spectrum after pumpdown to a pressure of $2.5 \times 10^{-8}$ torr. The upper scan has 0.1 the sensitivity of the bottom scan. 


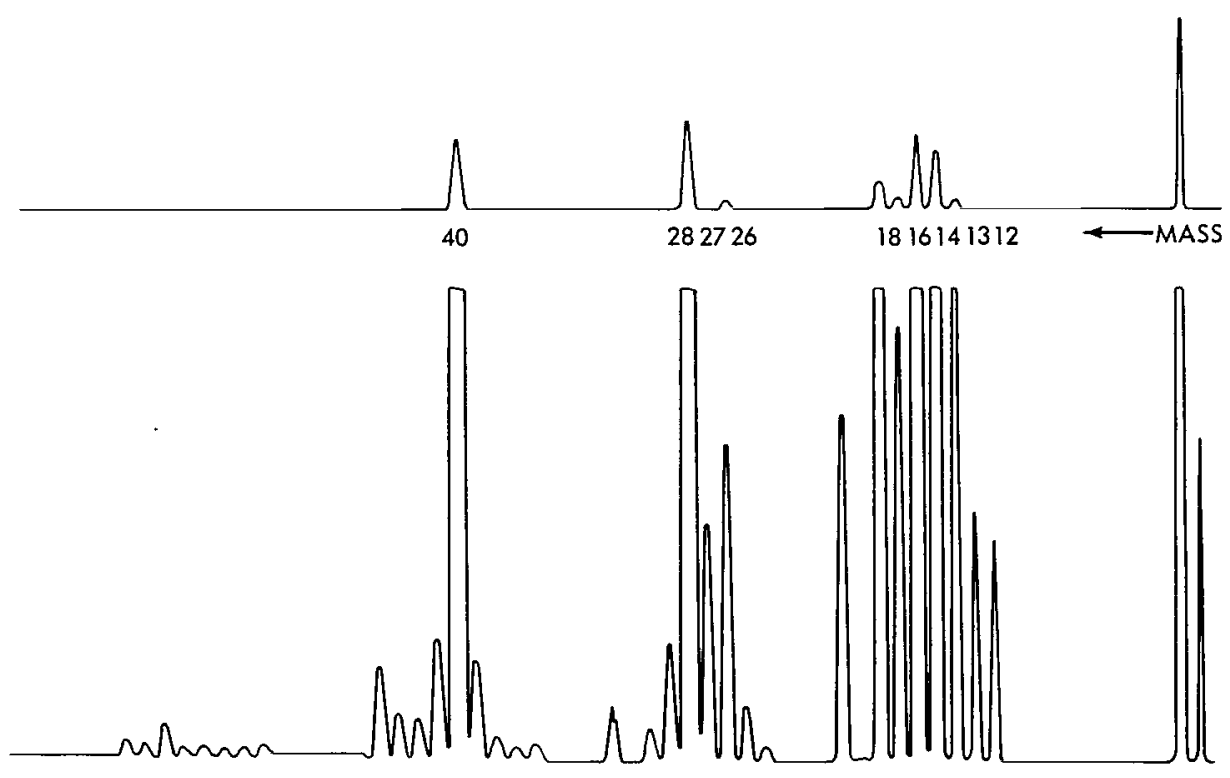

Figure 3-Gas composition at $1 \times 10^{-7}$ torr with a $\mathrm{CH}_{4}$ inbleed. The attenuation ratio of the upper to the lower scan is $25 / 1$.
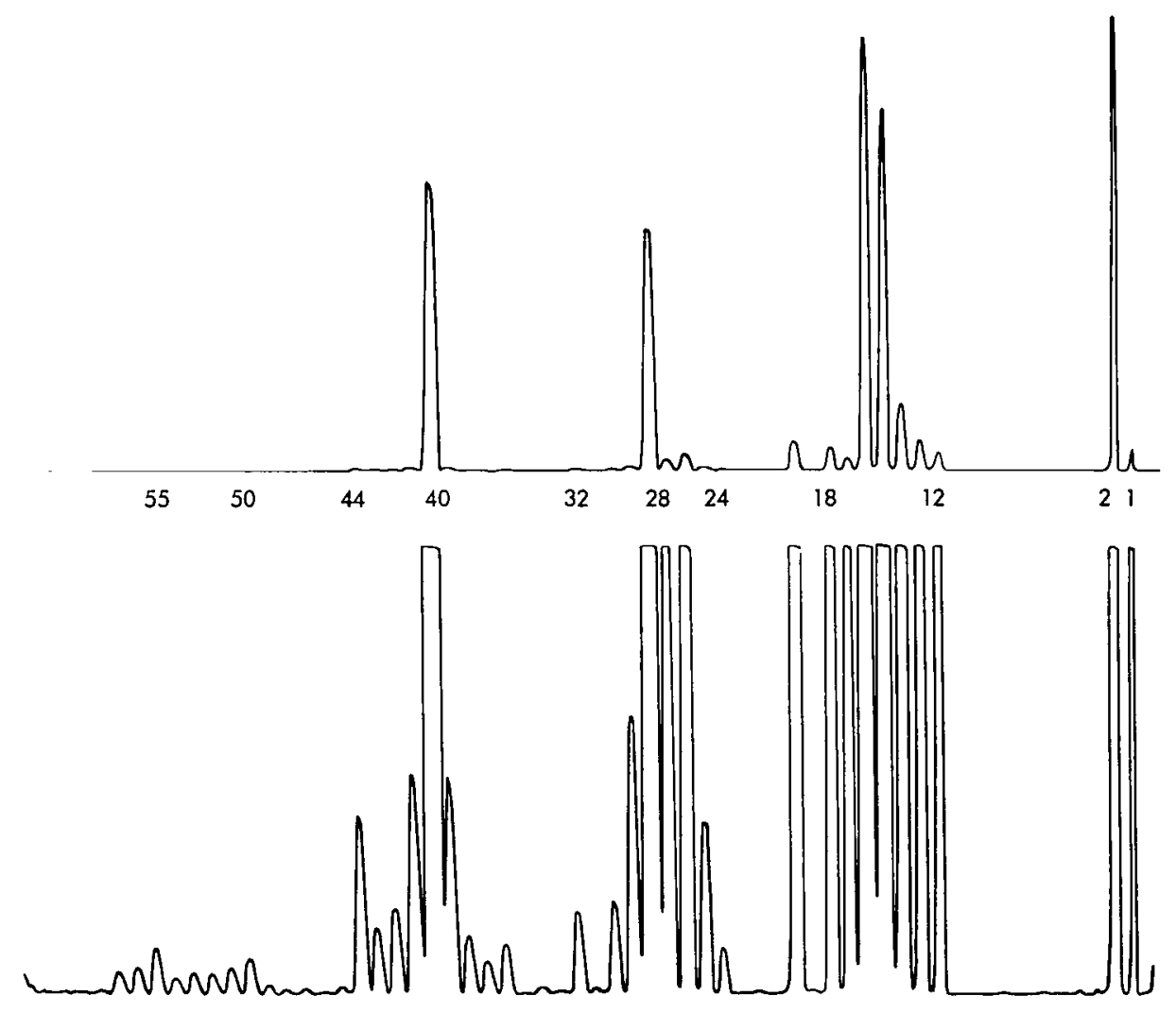

Figure 4-Gas composition at $6 \times 10^{-7}$ torr with a $\mathrm{CH}_{4}$ inbleed. The attenuation ratio of the upper to the lower scan is $50 / 1$. 


\section{OBSERVATIONS}

This study was undertaken because of a difference in pressure readings between the mass spectrometer and two Redhead cold-cathode gauges which were part of an ultra-high vacuum system for studying cryosorption techniques. The gauges read $5 \times 10^{-13}$ torr, while the spectrometer partial pressures additively indicated $10^{-11}$ torr. Other evidence indicated that the gauges were correct; hence the need for a closer analysis of the mass spectrometer data.

The scans taken during the chamber test showed hydrocarbons to mass 40 . In such a system at $20^{\circ} \mathrm{K}$, one would not expect to find even a trace of methane or ethane. Many investigators have found sources adding to the residual gases in ultra-high vacuum systems. Absorption and desorption mechanisms have been studied (Reference 3), gas-metal surface interactions have been explained (Reference 4), and gas evolution from electron multipliers has been observed (Reference $5)$. These reactions have for the most part been studied with the mass spectrometer, with the classical hot tungsten filament as the source of ionizing electrons. Hickmott (Reference 6) showed the hot tungsten filament to be a source of atomic, and therefore reactive, hydrogen. Young (Reference 7) showed that the carbon which is present as impurity or as carbides in tungsten filaments is reactive, at least with $\mathrm{O}_{2}$ to give $\mathrm{CO}$ and $\mathrm{CO}_{2}$. From an elementary point of view,

$$
\begin{gathered}
3 \mathrm{C}+2 \mathrm{O}_{2} \rightarrow 2 \mathrm{CO}+\mathrm{CO}_{2} \\
\mathrm{CO}+6 \mathrm{H} \rightarrow \mathrm{CH}_{4}+\mathrm{H}_{2} \mathrm{O} \\
\mathrm{CH}_{4}+\triangle(\text { Heat }) \rightarrow \mathrm{CH}_{3}^{+}+\mathrm{CH}_{2}^{+}+\mathrm{CH}^{+} \\
\mathrm{CH}_{3}^{+}+\mathrm{CH}_{3}^{+} \rightarrow \mathrm{C}_{2} \mathrm{H}_{6}, \text { etc. }
\end{gathered}
$$

It is thus possible to write an equation whose result is a hydrocarbon. The end products should vary with temperature, as (3) indicates. Table 1 was constructed to show the variation of the four most abundant whole molecular species with filament temperature. The data were taken from a dynamic system, and although efforts were made to hold the pressure constant at the operational level, it is practically impossible to read the ion pump gauge as closely as is required for the lower pressure measurements. Literature values for the ratios of methane to ethane to propane under similar circumstances are given as 100:15:1 (Reference 7); but we find these ratios to be more nearly 300:1:1 over a wide range of methane partial pressures. With the single exception of $\mathrm{H}_{2}$, acetylene appeared to be the most abundant daughter molecule throughout the dozens of individual scans. The following simple mechanism is suggested for the reaction methane $\rightarrow$ acetylene:

Metathesis:

Radical-Radical:

$$
\begin{aligned}
\mathrm{CH}_{3} \cdot+\mathrm{CH}_{3} \cdot \rightarrow \mathrm{C}_{2} \mathrm{H}_{5} \cdot+\mathrm{H} \\
\mathrm{CH}_{3} \cdot+\mathrm{C}_{2} \mathrm{H}_{5} \cdot \rightarrow \mathrm{C}_{2} \mathrm{H}_{4}+\mathrm{CH}_{4}
\end{aligned}
$$

Recombination and disproportion: $\mathrm{C}_{2} \mathrm{H}_{4}+\mathrm{C}_{2} \mathrm{H}_{4} \rightarrow \mathrm{C}_{2} \mathrm{H}_{2}+\mathrm{C}_{2} \mathrm{H}_{6}$ 


\section{Table 1}

Change in Peak Height* with Increasing Filament Temperature.

\begin{tabular}{|c|c|c|c|c|c|}
\hline \multicolumn{4}{|c|}{$1 \times 10^{-7}$ Torr } & \multicolumn{2}{|c|}{$7 \times 10^{-7}$ Torr } \\
\hline Parent & $\mathrm{m} / \mathrm{e}$ & Peak Height (mv) & $\%$ of $\mathrm{m} / \mathrm{e}=16$ & Peak Height (mv) & $\%$ of $\mathrm{m} / \mathrm{e}=16$ \\
\hline & & \multicolumn{4}{|c|}{ Emission Current $=1 \mathrm{ma}$} \\
\hline Methane & 16 & 639 & 100 & 4814 & 100 \\
\hline Acetylene & 26 & 32 & 5.0 & 149 & 2.5 \\
\hline Ethane & 30 & 4 & .63 & 18 & .39 \\
\hline Propylene & 41 & 7 & 1.09 & 31 & .65 \\
\hline Propane & 44 & 7 & 1.09 & 28 & .58 \\
\hline & & \multicolumn{4}{|c|}{ Emission Current $=2 \mathrm{ma}$} \\
\hline Methane & 16 & 2575 & 100 & 9225 & 100 \\
\hline Acetylene & 26 & 15 & .59 & 240 & 2.9 \\
\hline Ethane & 30 & 4 & .15 & 29 & .32 \\
\hline Propylene & 41 & -6 & -.20 & 48 & .52 \\
\hline Propane & 44 & -5 & -.18 & 36 & .39 \\
\hline & & \multicolumn{4}{|c|}{ Emission Current $=3 \mathrm{ma}$} \\
\hline Methane & 16 & 1725 & 100 & 13450 & 100 \\
\hline Acetylene & 26 & 25 & 1.5 & 250 & 2.0 \\
\hline Ethane & 30 & 8 & .46 & 28 & .2 \\
\hline Propylene & 41 & 5 & .29 & 55 & .4 \\
\hline Propane & 44 & 20 & 1.15 & 20 & .15 \\
\hline
\end{tabular}

* All peak heights listed are subtracted from previously measured backgrounds. Negative values indicate a drop in peak height from background.

Although these free radical reactions may be doubtful, they do give rise both to acetylene and to higher hydrocarbon species.

To check the accuracy of the observations during these experiments and to insure the proper functioning of the spectrometer, the fragmentation pattern for methane was compared to that published in the American Petroleum Institute (API) Tables (Reference 8). Table 2 lists the pattern obtained by three laboratories for the methane spectra under their respective serial numbers in

Table 2

Methane Fragmentation Patterns from API Tables.

\begin{tabular}{|c|c|c|c|c|} 
M/e & Serial \#1 & Serial \#60 & Serial \#110 & Experiment Average \\
12 & 2.36 & .82 & 2.64 & 2.7 \\
13 & 7.84 & 2.93 & 8.56 & 6.6 \\
14 & 15.8 & 7.52 & 17.1 & 14.9 \\
15 & 84.8 & 75.4 & 85.6 & 85.1 \\
16 & 100. & 100. & 100. & 100.
\end{tabular}

Last Column is Average Results from this Experiment. 
the API Tables; the last column records the average experimental results. It is interesting to note the divergence of serial no. 60; it illustrates the wide variety of fragments which can arise from instruments operating under somewhat different conditions.

\section{CONCLUSIONS}

We have found that hydrocarbons to $\mathrm{m} / \mathrm{e} 44$ have thermogenic origins as a result of the introduction of a hot filament into the vacuum. Homologous and derivative hydrocarbons are synthesized through free radical formation at the hot surface, and remain in the environment as the molecular species. Hence, ultra-high vacuum measurements with hot filament instrumentation are subject to errors arising from interaction of the sensed gas with the filament.

The usual technique for hydrocarbon decontamination of vacuum vessels is baking and prolonged pumping. The electron tube industry reports on residual gases are replete with studies performed with the Omegatron and similar hot filament spectrometers. Many of these reports list hydrocarbons beginning with $\mathrm{CH}_{4}$ among the residual gases, even when the pumping system fluid used for evacuation is mercury. Frequently the experimental layout removes the spectrometer from the vicinity of the tube under test by means of long tubes, with the pumping system between. Under such circumstances of limited conductance, it could logically be assumed that a build-up of these synthesized hydrocarbons would occur and be measured. The use of rhenium and tantalum filaments, or such low work-function materials as lanthanum boride and thoriated tungsten, appear to be indicated as preferred ionizing sources because surface temperature of the filament is a factor in these syntheses. Cold cathode gauges should give more reliable pressure measurement. Recent work (Reference 9) indicates that field effect ion sources for mass spectrometry offer a solution to the problem of minimal interaction between environment and instrument.

Goddard Space Flight Center

National Aetonautics and Space Administration

Greenbelt, Maryland, July 11, 1966 124-09-04-04-51

\section{REFERENCES}

1. Wolsky, S. P. and Zdanuk, E. J., "The Investigation of Residual Gases in Vacuum Systems," Vacuum 10(1/2):13-21, Feb.-Apr. 1960.

2. Young, J. R., "Interaction of Oxygen With Incandescent Filaments," J. Appl. Phys. 30(II):16711673, November 1959.

3. Reich, G., "The Influence of Adsorption and Desorption on Measurements of Low Pressures," in: Transactions of the 7th National Symposium on Vacuum Technology, 112-116, New York: Pergamon Press, 1960. 
4. Roberts, R. W., and P. E. McElligott, "Design and Construction of a Modulated Molecular Beam Mass Spectrometer," in: Transactions of the 10th National Vacuum Symposium of the American Vacuum Society, 407-410, New York: Pergamon Press, 1963.

5. Kendall, B. R. F., "Current-induced Gas Evolution, from Electron Multipliers," J. Vacuum Sci. and Tech. 2(1):1-5, Jan.-Feb. 1965.

6. Hickmott, T. W., "Interaction of Hydrogen with Tungsten," J. Chem. Phys. 32(3):810-823, March 1960.

7. Klopfer, A., Garbe, S., and Schmidt, W., "Residual Gases in Vacuum Systems," Vacuum 10(1/2):7-12, Feb.-Apr. 1960.

8. American Petroleum Institute. Research Project 44. Numerical Index. Pittsburgh Petroleum Research Laboratory, Carnegie Institute of Technology, 1955-19 .

9. Beckey, H. D., "Field Ionization Mass Spectroscopy," in: Advances in Mass Spectrometry, Vol. 2:1-23, New York: Pergamon Press, 1963. 
"The aeronautical and space activities of the United States shall be conducted so as to contribute. . . to the expansion of buman knowledge of phenomena in the atmosphere and space. The Administration shall provide for the widest practicable and appropriate dissemination of information concerning its activities and the results thereof."

- National Aeronautics and Space ACt of 1958

\section{NASA SCIENTIFIC AND TECHNICAL PUBLICATIONS}

TECHNICAL REPORTS: Scientific and technical information considered important, complete, and a lasting contribution to existing knowledge.

TECHNICAL NOTES: Information less broad in scope but nevertheless of importance as a contribution to existing knowledge.

TECHNICAL MEMORANDUMS; Information receiving limited distribution because of preliminary data, security classification, or other reasons.

CONTRACTOR REPORTS: Technical information generated in connection with a NASA contract or grant and released under NASA auspices.

TECHNICAL TRANSI.ATIONS: Information published in a foreign language considered to merit NASA distribution in English.

TECHNICAL REPRINTS: Information derived from NASA activities and initially published in the form of journal articles.

SPECIAL PUBLICATIONS: Information derived from or of value to NASA activities but not necessarily reporting the results of individual NASA-programmed scientific efforts. Publications include conference proceedings, monographs, data compilations, handbooks, sourcebooks, and special bibliographies.

Details on the availability of these publications may be obtained from:

SCIENTIFIC AND TECHNICAL INFORMATION DIVISION

NATIONAL AERONAUTICS AND SPACE ADMINISTRATION

Washington, D.C. 20546 